\title{
MQL Machining with nano fluid: a review
}

\author{
Pralhad B. Patole ${ }^{1, *}$, Vivek V. Kulkarni ${ }^{2}$, and Sudhir G. Bhatwadekar ${ }^{2}$ \\ ${ }^{1}$ Department of Mechanical Engineering Bharati Vidyapeeth's College of Engineering, Kolhapur, Maharashtra, India \\ 2 Department of Mechanical Engineering Sanjay Ghodawat Group of institution, Kolhapur, Maharashtra, India
}

Received: 14 October 2020 / Accepted: 6 April 2021

\begin{abstract}
In any metal cutting machining operation, the cutting fluid plays important role by cooling the cutting tool and the surface of the work piece, also chips are removed from heat affected zone. However, misuse of the cutting fluid and wrong methods of its disposal can affect human health and the environment badly. This paper presents a review of the important research papers published regarding the MQL-based application of mineral oils, vegetable oils and nano fluid-based cutting fluids for different machining processes, such as, drilling, turning, milling and grinding, etc. Most of the experimental studies have shown that application of MQL produces surface better than the flood and dry machining. In turning operation, parameters such as cutting speed, depth of cut, feed rate and tool nose radius have great impact on the surface finish. During high speed turning of steel inherently generates high cutting zone temperature. Such high temperature causes dimensional deviation and failure of cutting tools, surface and subsurface micro cracks, corrosion etc. Therefore, with proper selection of the MQL system and the cutting parameters, it is possible for MQL machining with minimum cost and less quantity of coolant to obtain better conditions, in terms of lubricity, tool life, cutting temperature and surface finish. The findings of this study show that MQL with nano fluid can substitute the flood lubrication for better surface finish.
\end{abstract}

Keywords: Minimum quantity lubrication / nano fluid / machining / surface roughness etc.

\section{Introduction}

In recent times, modern machining industries are trying to achieve high quality, dimensional accuracy, surface finish, high production rate and cost saving along with reduced environmental impact. In the machining process, one of the commonly carried out operations is a turning. It can be carried out on variety of machines like lathe, special purpose machine or CNC machine. The quality of turning is measured in terms of tolerances and roughness of surface. Surface finish is a quality specified by customer for machined parts [1]. There are many parameters that affect surface roughness, but most are difficult to quantify adequately. In turning operation, parameters such as cutting speed, depth of cut, feed rate and tool nose radius have great impact on the surface finish [2]. The turning operation seems very simple; through high speed turning of steel inherently generates high cutting zone temperature. Such high temperature causes dimensional deviation and premature failure of cutting tools. It also impairs the surface integrity of the product by inducing tensile residual

\footnotetext{
*e-mail: pb.patole@rediffmail.com
}

stresses and surface and subsurface micro cracks in addition to rapid oxidation and corrosion [3].

A cooling lubricant is used in turning operation to reduce friction at tool chip and work piece interface. However, in high speed machining, conventional cutting fluid application fails to penetrate the chip tool interface and thus cannot remove heat effectively The lubricant has a strong effect on machined surface quality and tool wear. The costs related to cutting fluid represent a large amount of total machining cost; also cause health of machining operator and correct disposal [4]. However, at present complete elimination of cutting fluid is not possible. An alternative to conventional flood machining is the application of cutting fluids, in very small quantities to the small area where actual machining takes place. This technique is known as minimum quantity lubrication (MQL). In MQL the heat removal can be done and it also provides sufficient lubrication to prevent the generation of heat and reduces environmental impact [5].

The recent development of nano fluids provides alterative cutting fluids which can be used in MQL machining. The advanced heat transfer and tribological properties of nano fluids can provide better cooling and lubricating in the MQL machining process, and make it production-feasible. 
With proper selection of the MQL system and the cutting parameters, it is possible for MQL machining with minimum cost and less quantity of coolant to obtain better conditions, in terms of lubricity, tool life, cutting temperature and surface finish [6]. Demand for better surface finish and accuracy has been increasing rapidly in recent years. To improve the surface characteristics from micro level to nano level, nano fluids are useful in the machining process.

\subsection{Need for advanced coolant and cooling technique}

In the present scenario, the metal cutting industries are shifting towards good dimensional accuracy, achieve quality surface finish, and cost saving with reduced environmental impact. Also, metal cutting industries are trying to design of manufacturing products with increased variety and low volumes. With the advancement of machine tools and cutting tools better surface finish is ensured but efforts are required for cost reduction. It is reported that about $16-20 \%$ cost is involved in lubrication system which can be reduced. Therefore, use of advanced coolant and cooling techniques is required to achieve better surface roughness, tool life and maintain the degree of cutting temperature and cutting force. Traditionally, the conventional cooling system is designed for machining such as to carry away the heat and improve machining characteristics. However, such flood cooling systems have some limitations and drawbacks are as follows:

- The costs related to cutting fluid represent a large amount of total machining cost and have a problem of coolant disposal [5].

- Conventional cutting fluid method fails to penetrate the tool chip interface and cannot be removed heat effectively [6].

- High temperature causes dimensional deviation and premature failure of cutting tools [4].

- High temperature induces tensile stresses into the surface integrity of the product and surface micro cracks [4].

There are two approaches to minimize the above problems and reduce the cooling cost are as follows:

- Selecting suitable lubricating system such as Minimum Quantity Lubrication.

- Selecting suitable coolant having better lubricating properties such as nano fluid.

In the high variety and low volume production system, MQL with nano fluid is becoming a prospective way of reducing the unit cost of the product. MQL with nano fluid technique reduces cooling cost, environmental effect and problem of disposal as compared to conventional flood system. The MQL with nano fluid lubrication system must be readily adaptable, must be able to accommodate in the machining operation. Therefore, MQL with nano fluid is one of the promising cooling systems and need to be explored.

\section{Literature review on different cooling systems}

In the machining process, research of advanced coolant and cooling technique is required. Research into the machining field is mainly driven by the need to improve cutting and cooling techniques. Such a research study in machining may further results into improvements in the productivity, and efficiency of production. Many researchers have reported effects of cutting parameter on surface roughness, different cooling systems with conventional cutting fluids in machining processes. The aim of the present research work is to study the effect of process parameters under Minimum Quantity Lubrication mode with nano fluid. The literature review is broadly classified under the following categories such as dry, conventional flood and MQL system. The review of the effect of lubrication system on the machining of specific material alloy steel AISI 4340 is also presented.

\subsection{Dry system}

The literature review carried out related to the dry system is as follows:

Huang and Liu (2003), have studied the research work of machining characteristics and surface integrity of advanced ceramics, including alumina, under high speed deep grinding conditions. The excess material removal in the grinding of alumina-titania was dominated by grain dislodgement. It was observed that at a feed rate of $500 \mathrm{~mm} / \mathrm{min}$ and an increase in the wheel depth of cut from $0.1-2 \mathrm{~mm}$ improved the ground surface finish [7]. Mauvoisin et al. (2003), have developed a drilling method for the measurement of the hardness for surface heat treated steels was based on the proportionality between material hardness and drilling thrust. The parameters other than hardness related parameters to the material can improve the cutting thrust level. In the research work, to study the influence of the microstructure, the ductility, the toughness and the work hardening of material on the drilling thrust, a few tests were carried out. Tensile and impact tests were carried out on various materials [8]. Xie et al. (2006) have performed the experimental work on titanium alloy in dry machining. The authors have studied the effect of process parameters such as feed rate; cutting speed, depth of cut on cutting temperature and cutting force. In the analysis, the authors found that higher depth of cut produces maximum cutting force. They have shown cutting temperature factor affects on tool life [9]. Devillez et al. (2007), has chosen the orthogonal cutting process for the research work. In the research work the cutting forces and feed components were measured. The cutting ratio was shown to be as an indicator of tool wear. The tool wear were analyzed by using white light interferometer and scanning electron microscopy. The ability of the different coatings to increase the carbide tool performance was analyzed. The results obtained from uncoated tools were compared with coated tools under the similar conditions of machining [10]. $\mathrm{Li}$ et al. (2007) have studied the effect of process parameters on medium carbon steel material in dry machining. The authors determined the temperature rise and tool wear while turning operation of medium carbon steel by high-speed steel cutting tool at various depth of cut. The spindle speed and feed rate have been kept constant. It was observed that the air flow rate has a significant role on tool life than the oil flow rate under MQL 


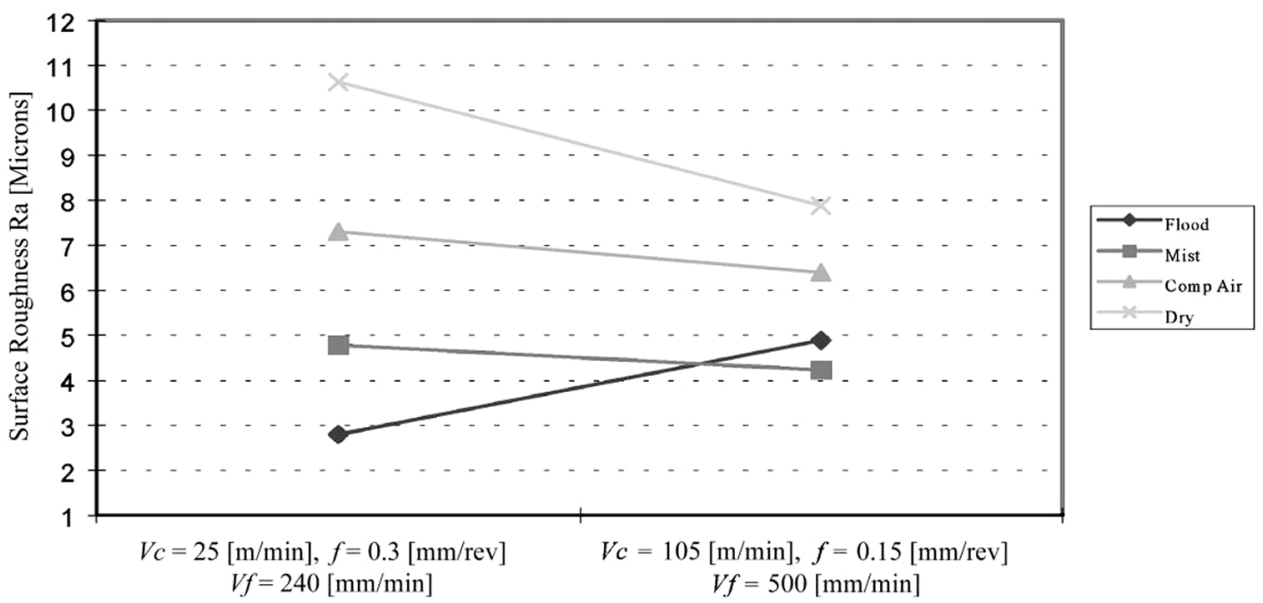

Fig. 1. Comparison of average values of surface roughness against varying speeds and feed rates (Kelly and Cotter [22]).

conditions in the research work [11]. Sripathi (2009) discussed that oblique machining can be modified to form a tube turning orthogonal system for the ease of understanding, modeling, and analysis of forced component. Orthogonal tube turning experiments have been performed to measure the variables such as cutting forces, chip geometry, shear cutting temperature [12]. Nalbant et al. (2009) have performed the research work on material AISI 1030 steel in dry machining with a constant depth of cut. They also studied the effect of cutting parameters on surface roughness. The researchers concluded that feed rate plays an important role in achieving good surface roughness. The surface roughness value has been determined by the ANN with acceptable accuracy [13]. Jawahir et al. (2011), have reported recent progress in theoretical and experimental results on surface integrity in metal cutting processes. Therotical and Experimental techniques for measuring different surface parameters were presented. Results from a Round Robin Study on surface parameters such as roughness and hardness, in grinding, turning, and milling were then presented [14]. Laval et al. (2012) have carried out the experimental work on AISI202 in dry machining and studied the effect of process parameters such as cutting speed, feed rate and depth of cut on surface roughness. It was found that during high-speed turning operation maximum temperature generated [15]. Sharma and Pandey (2015), have been developed hybrid textures on carbide inserts. The experimental investigations have been performed to study the effect of differently textured cutting inserts while machining 4340 hardened steel. $\mathrm{CaF}_{2}$ has been used as a solid lubricant to self-lubricating in nature. The comparative analysis showed the cutting forces, the roughness of the machined work piece and chip thickness ratio gets significantly reduced by using the developed cutting inserts [16]. Pramanik and Guy (2015), concluded that the deformation in machining of titanium alloys was critical and cause basic problems, such as high stress on cutting tool, saw tooth chips, more temperature, and poor tool wear undercut parts. These tasks were affected by each other. Also, it was observed that saw tooth chips cause variation in thrust cutting forces which results in cyclic stress on machine and cutting tools. The less thermal conductivity of titanium alloy causes for temperature rise. Thus, improvements in turning of titanium alloy depend on the inherent properties of the alloy [17].

\subsection{Conventional flood system}

The literature review carried out related to flood system is as follows:

Sahoo and Sahoo (2013) carried out the research work deals with machinability studies on cutting forces, surface finish, and flank wear in finish turning of AISI 4340 steel. The authors found that the turning forces are observed to be lower as compared to uncoated carbide insert [18]. Dahu et al. (2013), have performed the experimental work and focused on the tool wear characteristics in the machining of nickel-based super alloys. The authors concluded that to control the tool wear and its life, tool coating, tool materials, tool geometry, cutting parameters has been verified to be effective. It has been found that tool wear control is not only related to the machining time but also closely associated with the geometrical parameters of the tool. Also, tool wear depends on the cutting parameters and the physical and chemical properties of work piece material. Moreover, the cooling methods and the cutting fluid types are employed to effectively control tool wear [19]. Debnath et al. (2015) have performed the experimental work related to the developments in bio-based cutting fluids by using various vegetable oils in machining. The authors found that the bio-based cutting fluids have significantly reduced the ecological problems caused by mineral-based cutting fluids. These cooling methods minimized the quantity of cutting fluids used in machining operation during cutting performances compared to wet cooling systems [20]. Simunovic et al. (2015) have concluded that the influence of input variables such as depth of cut, speed, and feed rate on the surface roughness of structural steel. The authors have obtained the result of better quality of surface roughness in dry and cooling machining processes than in low-pressure flood cooling. The authors also found that in low-pressure flood cooling suppressing chips on the tool edge occurs as well as vibrations and increase the surface roughness value [21]. 


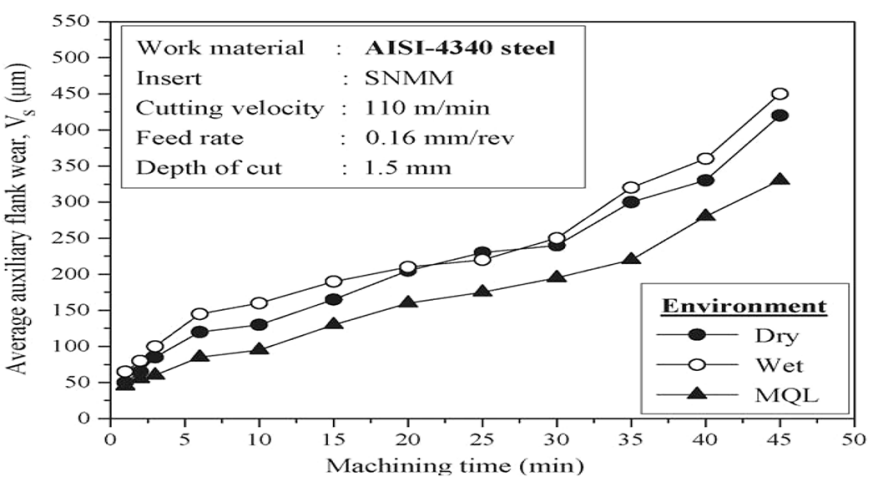

Fig. 2. Average auxiliary flank wear $V$ s time under dry, wet and MQL conditions (Dhar et al. [3]).

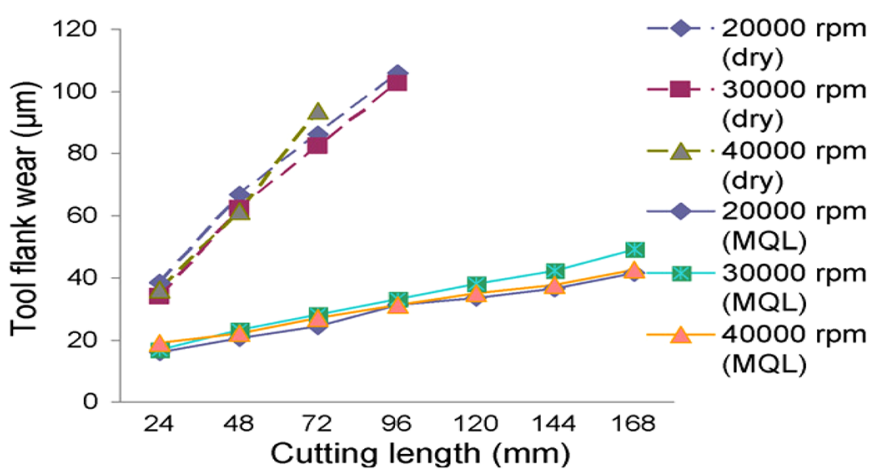

Fig. 3. Tool flank wears under dry and MQL conditions (feed is $1 \mathrm{~mm} / \mathrm{rev}$ ) (Li et al. [11]).

\subsection{MQL system}

The literature review carried out related to MQL system is as follows:

Kelly and Cotter (2002) have done the experimental work on material aluminum alloy in MQL mode. By using cutting speed, feed rate and depth of cut process parameters they have analyzed response variables cutting temperature and chip morphology. By carrying out the experimental work the researchers found that at lower feed rate better surface roughness can be achieved. Figure 1 shows comparison of average values of surface roughness against varying speeds and feed rates [22].

Dhar et al. (2006), from result analysis they have shown the growths of average auxiliary flank wear Vs with time of machining of the steel under dry, wet and MQL conditions in Figure 2. The nature of growth of VS matches with that of VB expectedly. The application of MQL has reduced VS, which is expected to provide better surface finish [4].

Ming Li et al. (2007), have studied the effect of process parameters on medium carbon steel material in dry machining and they determined the tool wear and temperature rise during turning operation of medium carbon steel by high speed steel cutting tool at different depth of cut, spindle speed and feed rate has always being constant. The reductions of tool flank wear lengths in MQL cutting compared to dry cutting are about $68 \%$ under all cutting speeds in this paper after cutting $96 \mathrm{~mm}$ long work

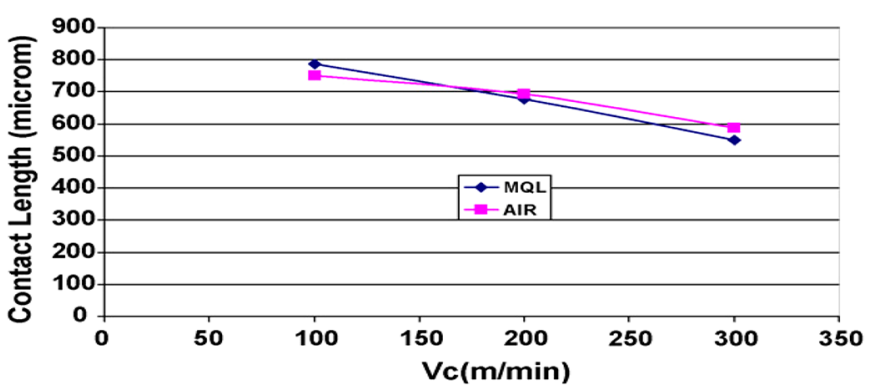

Fig. 4. Contact length values for MQL and compressed air at different speeds (six grov) (Tasdelen et al. [5]).

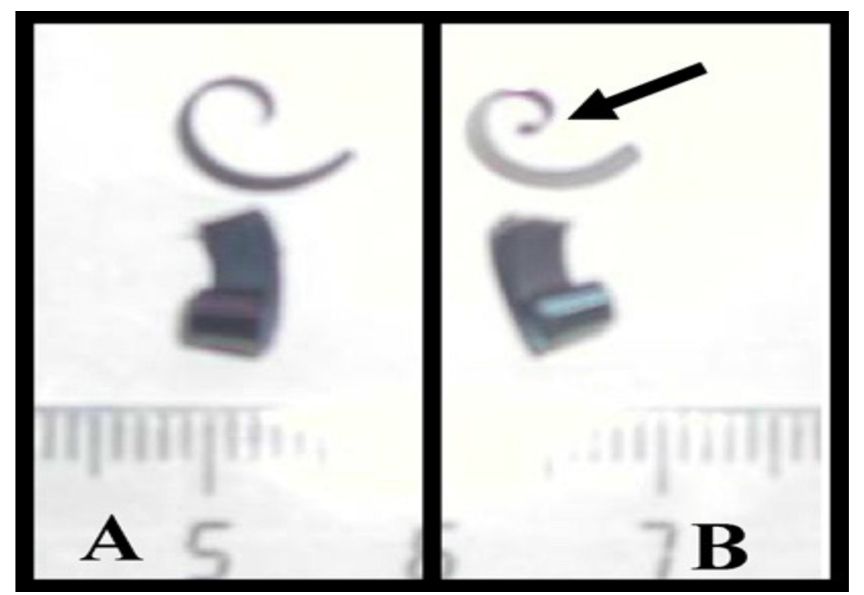

Fig. 5. Chip up-curl (12 grooves) for: (A) compressed air and (B) MQL (Tasdelen et al. [5]).

material. It is practical to presume the maximum tool flank wear of the micro-tools utilized in this study is according to Figure 3 [11].

Tasdelen et al. (2008), this research work deals with experimental work on 100Cr6 Steel material in MQL by using cutting parameters cutting velocity, feed rate and depth of cut. They analyzed chip morphology and calculate the metal removal rate. Figure 4 is the summary of the contact length measurement comparison. The difference between MQL and compressed air that resulted in different contact length was also observed in the chip shape. The oil droplets affect the contact in the beginning of chip formation that results in smaller radius of curvature in the head of the chips, as shown in Figure 5 [5].

Khan et al. (2009) studied the effects of MQL using vegetable oil-based cutting fluid on the turning performance AISI 9310 alloy steel as compared to wet and dry machining. Based on the results and experimental investigations MQL provided significant improvements, related to tools wear and surface finish. The MQL system enables to reduce chip-tool interface temperature up to $10 \%$ as compared to wet machining method. Surface roughness improved due to the reduction of wear by the application of MQL [23] Different cooling techniques are shown in Figure 6. Sharma et al. (2009) worked on cooling techniques for improved productivity in turning (AISI 4340) such as minimum quantity lubrication, cryogenic 


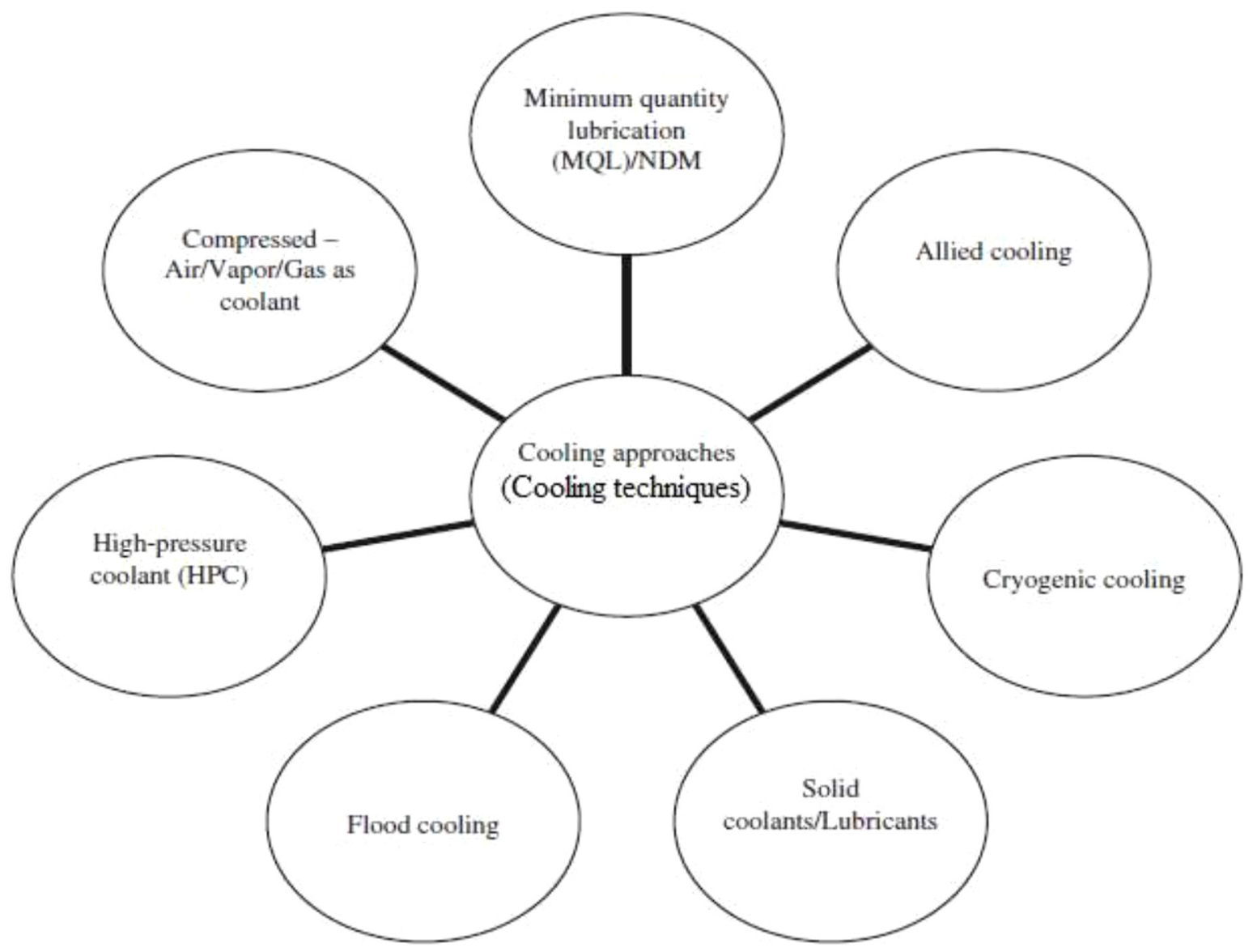

Fig. 6. Different cooling techniques (Khan et al. [23]).

cooling, compressed air cooling etc. This research article also presents an overview of the techniques such as neardry machining, MQL, high-pressure coolant, compressed air cooling, cryogenic cooling, and the use of solid lubricants. The authors concluded that these methods were useful in a reduction in heat and friction at the cutting zone [24].

Obikwa et al. (2009) have used Inconel 718 material in the experimental work with oil mist spray and studied the effect of cutting parameters on surface roughness. The authors concluded that low feed rate and spindle speed produce better surface roughness [25]. Abdul Hasib et al. (2010), carried out the research work to develop a mist application device to apply cutting fluid for turning operation of medium carbon steel. It is found that at high cutting speed, depth of cut and at constant feed rate the tool wear and temperature during turning operation is maximum. Also mist application system with the present technique has reduced flank wear and improves tool life. The Figure 7 shows the effect of mist application on turning zone temperature under different speed and depth of cut as compared to dry and flood conditions [26].

Kug Young et al. (2010) presented the work on the investigation into the MQL and wet turning process of AISI 1045 material. The objective of this research work is to suggest the experimental model in order to predict the cutting force and surface roughness. From experimental

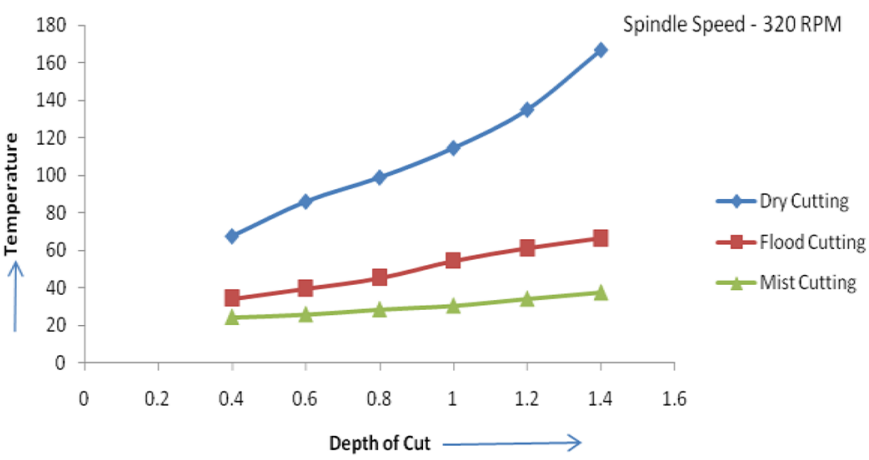

Fig. 7. Temperature Vs Depth of Cut (Spindle Speed $=320$ RPM) (Obikwa et al. [25]).

work cutting force and surface roughness were measured and the measured data analyzed by regression analysis. Figure 8 shows the difference of principal cutting force in MQL and wet turning processes. Experiments 6, 7, 14, 16, 17 and 27 show higher cutting force and their results are different from those of the experiment condition that have poor surface roughness. In the case of higher cutting force, experiments 14, 16, 17 and 27 have the same feed rate $(0.2 \mathrm{~mm} / \mathrm{rev})$ and depth of cut $(1.2 \mathrm{~mm})$. Experiments 20 , 21 and 28 show a lower cutting force with the same depth of 


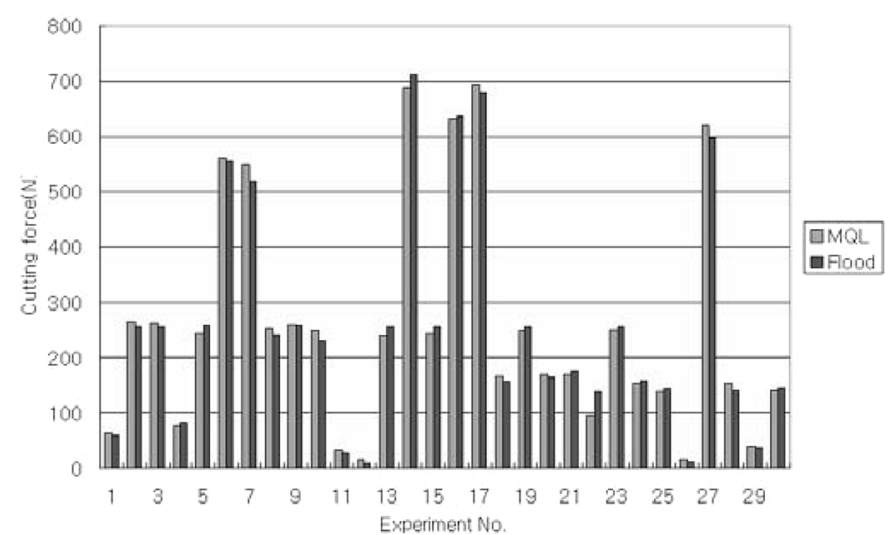

Fig. 8. Comparison plots of cutting force according to cooling lubrication environment (Kug Young et al. [27]).

cut $(1.2 \mathrm{~mm})$, but a different feed rate $(0.02 \mathrm{~mm} / \mathrm{rev})$. It was confirmed that cutting force deteriorated with the combination of specific cutting conditions [27].

Cetin et al. (2011), have used different types of six cutting fluids, four from canola oils and sunflower with different ratios of extreme pressure additives. Cutting fluid type, cutting speed, and depth of cut was considered as process parameters. The tool regression analyses were applied to predict feed forces and surface roughness. The results of commercial cutting fluids are compared [28]. Kaynak et al. (2013), have presented the study of cryogenic cooling system tool wear by comparing the results from cryogenic machining operation with results obtained from MQL lubrication and dry machining method. The flank wears at the nose radius resulting cutting performance criteria such as surface quality and force components of machined parts. The results from the research work shows that cryogenic cooling has an effect on controlling toolwear rate [29]. Yuan et al. (2011), have performed the experimental work on Ti-6-Al-4V material with MQL mode. The authors concluded that cutting force is less in MQL as compared to dry machining. Authors have carried out the analysis of tool wear and chip morphology and found that feed rate plays important role in producing lower surface roughness [30]. Barczak and Batako (2012) studied the research work related to cutting forces. They have found that lower tangential forces were recorded by MQL for the same material removal rate. Table 1 shows Research Summary of MQL Literature Review. This research study also reviews the application of the MQL technique in abrasive machining. It gives comparison of result between conventional and dry grinding. With a general purpose alumina wheel the common steels EN8, M2, and EN31 were ground. The results determined that MQL performance and flood delivery under the given conditions. In some conditions, MQL achieved better results as compared to other conditions [31]. Zeilmann et al. (2012), presented a study of drilling operation of the specimen AISI P20 steel. They have analyzed the effects on the process parameters caused by reducing the quantity of cutting fluid supply. The different machining strategy was adopted to solve the machining problem. The MQL method resulted in the lowest roughness values in regions of the

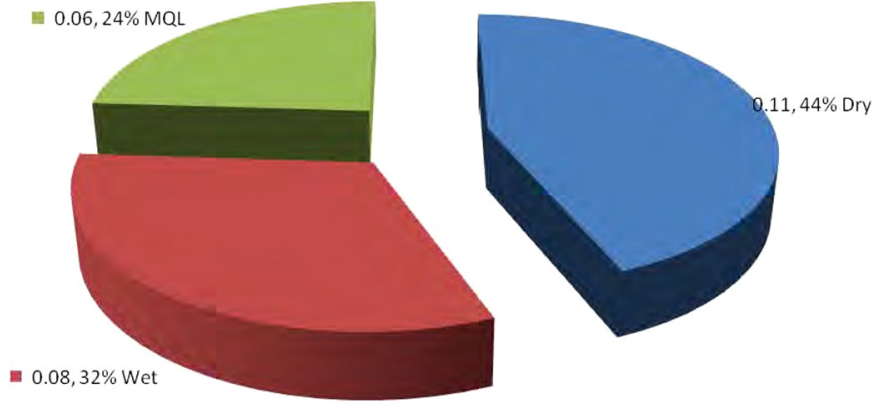

Fig. 9. Tool wear in various environmental conditions (Cetin et al. [28]).

holes [32]. Patil (2012), have worked on material AISI 4340 in different cutting environments and studied the effect of process parameters on surface roughness and tool wear. He has done the analysis on response variables such as surface roughness and tool wear. The pie chart (Fig. 9) shows the percentage wear at different cutting environment, cutting speed and feed [33].

Balan et al. (2013) investigated by using MQL technique considerably reduces the grinding forces, surface roughness and temperature as compared to dry technique. The research study was an experimental investigation of the significance of the MQL parameters on grinding performance of Inconel 751. Inconel was an ideal material for high-temperature applications which possesses difficulties during machining, especially grinding. It was found that better results were obtained for the optimal MQL condition in grinding in terms of reduced grinding force, temperature, and roughness [34]. Nath et al. (2013), have carried out the work on titanium material by using cutting fluid spray system. The authors have analyzed the effect of cutting parameters on cutting temperature, tool wear, and chip morphology. Table 2 shows Research Summary of MQL Machining with Nano fluid. The authors concluded that less tool wear occurs in the fluid spray system as compared to dry machining [35]. Mao et al. (2013), performed the experiment based on the atomization mechanism. In this study, the influencing factors velocity and the diameter of the droplet were analyzed. According to the heat transfer mechanism the grinding zone was divided into four different regions of the droplet at different surface temperatures. From the experimental result, the related mathematical models of heat transfer in the grinding zone were developed [36]. Rakurty et al. (2013) have performed the experimental work on AISI 1045 material by using MQL system. The researchers analyzed the effect of cutting parameters on surface roughness and cutting temperature. From result analysis, it is seen that better surface roughness obtained in MQL as compared to dry machining. The focus of this research was to understand the effect of simulating a flood coolant by targeting Minimum Quantity Fluid on rake and flank faces of the cutting tool [37]. Lawal et al. (2013) observed the effect of MQL using vegetable oil-based lubricants. They have analyzed various cooling techniques in machining operations and concluded that the MQL method is better than other lubrication systems. The authors have found 


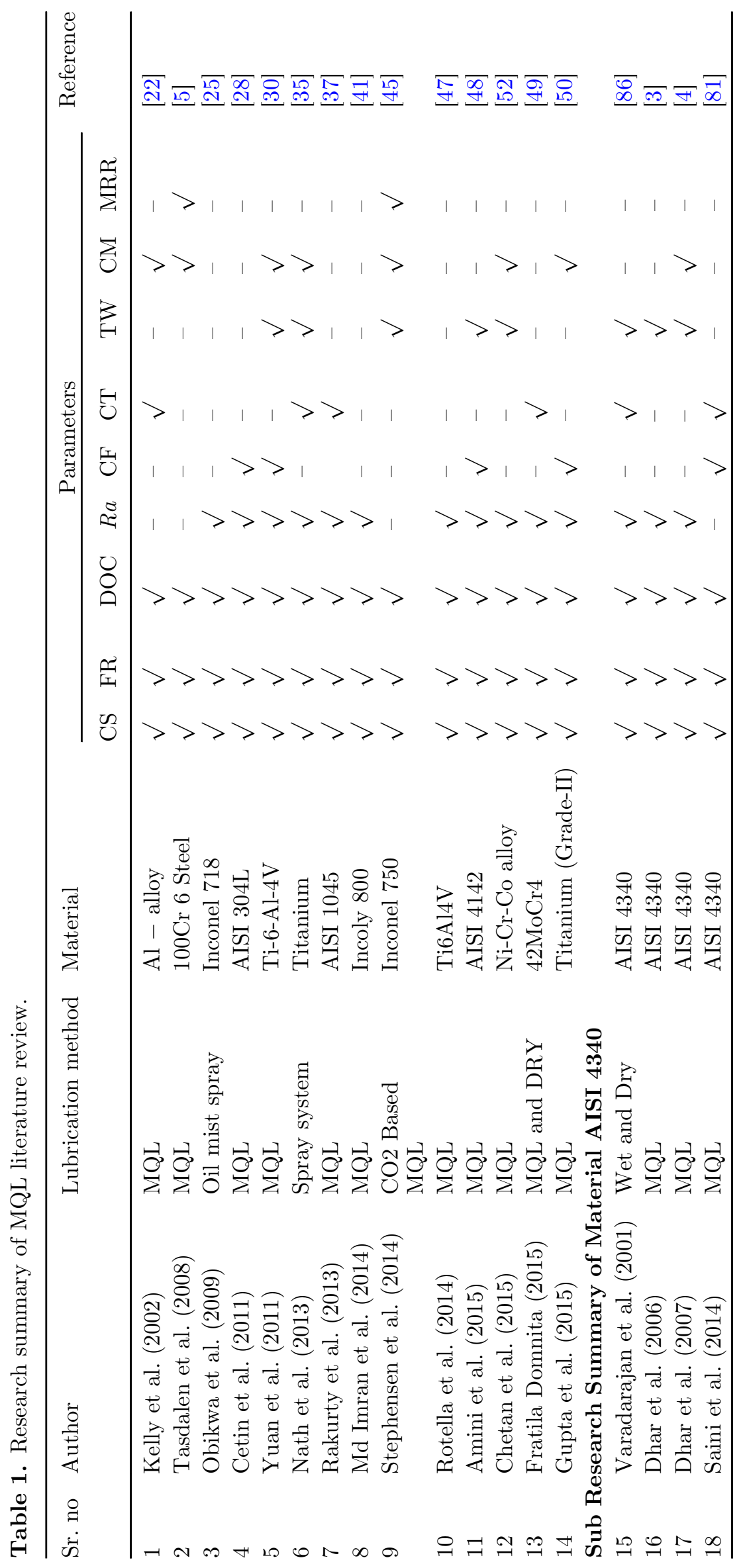




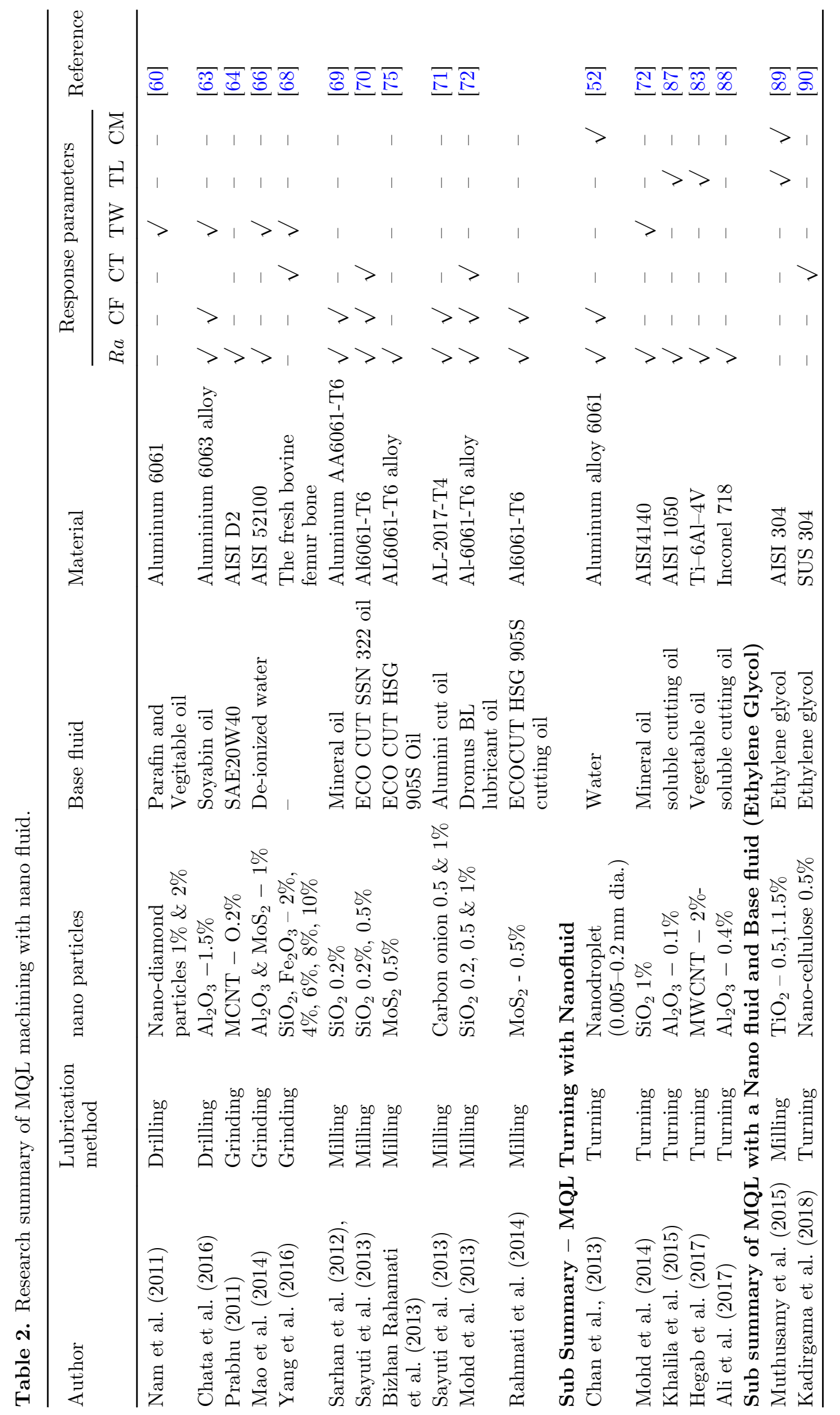


that the benefit of cutting fluids with respect to the surface finish of work piece, the cutting force, temperature, and tool wear, at the cutting zone [38]. Minton et al. (2013), have examined the formation of hot-spots on the rake face during near dry and dry turning operation of titanium using cemented carbide inserts. Cutting performance was examined by measurement of tool life and wear. The trials of research work were carried out with an internally cooled tool with, diamond coated insert. Thus, successfully heat carried away from the tool, due to recirculation of coolant through the tool holder. High thermal conductivity and low coefficient of friction of diamond, examined by the indirect cooling, results in higher tool life while maintaining better surface finish [39]. Komini Babu et al. (2013), have developed a new measurement device to measure the thermal conductivity of cutting fluids using the transient hot-wire technique. The instrument was designed such that the thermal conductivity could be measured using both single wire sensor of dual wire sensor and different length. The water was chosen as testing fluids for primary standards. The results of single wires compared, the thermal conductivity of the fluids measured was consistent with a dual-wire method [40]. Md Anasari and Kotiveerachary (2014) have worked on Incoly 800 material in MQL and studied the effect of cutting parameters on surface roughness. Taguchi method was used to optimize the cutting parameters based on surface roughness. The results were analyzed using ANOVA. Feed rate plays important role in producing lower surface roughness followed by cutting speed and depth of cut has the least significance in producing lower surface roughness [41]. Setti et al. (2014), have presented the combination of image processing techniques and microscopy to ascertain the quality of droplets by spraying the MQL fluid system onto an acrylic sheet. Some of the raw droplet features were captured with a stereo zoom microscope. The analysis was carried out by measuring the number of droplets per unit area and droplets size. The MQL application was achieved with optimum parameters such as fluid flow rate, the distribution of the droplets, nozzle tip, the applied air pressure, to machining zone distance [42]. Paolo et al. (2014), have studied the influence of the lubrication strategy on surface quality, tool wear, and environmental impact when turning and milling of the metallic alloys Ti-48Al- $2 \mathrm{Cr}-2 \mathrm{Nb}$. The results of dry cutting were compared to that of minimum quantity lubrication and wet conditions. The authors have concluded that dry machining requires minimum energy consumption and reducing to zero the lubricant consumption. From the selected cutting parameters and lubrication conditions, MQL appears to be an advantageous solution for milling [43]. Wang et al. (2014), investigated the grinding process under nano particle jet flow minimal quantity lubrication for the common grinding wheel. This study establishes a kinematics model, the plastic accumulation model and, the elastic deformation model of a single grinding wheel. The authors examine the effect of various grinding parameters on the surface of the work piece. Results showed that as the peripheral velocity of the grinding wheel increases the corresponding $R a$ and $R z$ heights decreases. Also, it is found that as the length of each crack increases, the number of grinding cracks on the surface of the work piece decreases [44]. Stephensen et.al (2014) have carried out the experimental work on Inconel 750 material by using $\mathrm{CO}_{2}$ based MQL. They have studied the effect of cutting parameters on tool wear and chip morphology. The authors have also calculated the metal removal rate. Finally, the researchers concluded that under MQL mode turning characteristics can be improved. When machining Inconel 750, the results indicate that $\mathrm{CO}_{2} \mathrm{MQL}$ can provide increased MRR compared to flood coolants. Similarly, $\mathrm{CO}_{2}$ MQL can provide for nickel alloys by changing the wear mechanism from rapid notch wear to gradual crater wear, improving lubricity [45]. Banerjee and Sharma (2014) have developed a mathematical model as a function of cutting speed and the feed rate for MQL machining. They have shown that the MQL technique is a better option than wet machining. In the research, work authors have obtained the tool-chip friction coefficients for various machining conditions through modeling. The validated model was utilized to different machining conditions, the contact length of the tool-chip interface temperature [46]. Rotella et al. (2014), have performed a study of machining of Ti6Al4V alloy under dry, cryogenic cooling conditions, minimal quality lubrication. The influence of the cooling conditions on the surface roughness and the product performance was studied. The work study carried out in terms of surface roughness, hardness, metallurgical conditions, including micro structure, phase transformation of the machined product grain refinement. From the results, it was observed that cooling conditions affect the surface of the product in improving the overall product performance [47]. Amini et al. (2015), have studied in the research work, improvement of MQL machining and its effect on tool wear in turning of AISI 4142. In the research work, surface finish was used as the response parameter of finding the optimal conditions of fluid flow rate, location and angle of the nozzle and frequency. The experiments were performed to study tool life after optimization. Surface roughness and machining force were chosen as the criteria to determine the tool life. Obtained results showed that the tool life in MQL was longer than that in dry machining [48]. Fratila Domnita (2015), has studied thermal phenomena in the turning process of $42 \mathrm{MoCr} 4$ alloyed steel with respect to cutting parameters under MQL mode. Also, comparison of result carried out under both environment-friendly cooling techniques (near dry cutting and dry cutting). For the validation of experiment a series of tests are conducted regarding cutting temperature measurement near to the cutting zone. Using Design Expert software, the effect of cutting conditions on the cutting temperature has been analyzed [49]. Gupta et al. (2015), have applied RSM and particle swarm optimization technique for optimizing the machining factors in turning of titanium alloy under MQL mode. The three process factors cutting speed; feed rate, and side cutting edge angle were selected whereas response parameters were selected as tool wear, tangential force, surface roughness [50]. Batako and Tsiakoumis (2015) have found that Minimum Quantity Lubrication produced a good surface finish as compared to dry grinding with vibrations for higher doc. Also, researchers have presented the results of low-frequency oscillatory grinding in dry and 
near- dry conditions. In the research work, nickel alloys and hardened steels were ground with vibration assistance. The grinding forces were solved together with the surface finish. The grinding wheel performance was given in terms of grinding ratio [51]. Chetan et al. (2015) have presented the manufacturing techniques in metal cutting industries for green and cleaner production. The authors concluded that the cutting process becomes more effective and environmentally friendly as there is ample research being done on MQL. This research work includes literature review of all the existing lubrication techniques in the metal cutting process. In this research work, the authors concluded that MQL gives less cutting temperatures, greater tool life as compared to conventional wet machining methods [52]. Sarıkaya and Güllü (2015) have optimized Minimum Quantity Lubrication parameters using grey relational analysis in turning operation. The researchers have achieved optimum value such as $180 \mathrm{ml} / \mathrm{h}$. the fluid flow rate and $30 \mathrm{~m} / \mathrm{min}$ cutting speed on the basis of surface roughness response characteristics. It was shown that the cutting performance were significantly improved using this approach [53]. Hassanpour et al. (2016), have been carried out the study during the micro-milling process on the surface integrity of titanium parts (Ti6Al4V) under various cutting conditions. The experiments were performed in the Minimum Quantity Lubrication condition using the micro tool with $0.5 \mathrm{~mm}$ in diameter. In addition, to have a better understanding of the results, the cutting force was measured. The input parameters of micro-milling such as feed rate, spindle speed and axial depth of cut were considered, each in three levels. The effect of input parameters on the surface roughness, burr width, and in-depth micro hardness as well as mean cutting force was evaluated. According to the results, cutting speed and feed per tooth had the highest impact on the surface integrity characteristics of this alloy [54]. Verma et al. (2017), performed the experimental work related to CFD based modeling of the aerosol. The aerosol produced by an internal mix nozzle was carried out. The different parameters are considered for the study such as droplet diameter, droplet velocity, and heat transfer coefficient. It was observed that higher flow rates helping in reduction of the grinding zone temperature. From the result, it is found that the intensity of the tensile residual stress and tangential grinding force were reduced [55]. Ramanuj Kumar (2018) has worked on the analysis of flank wear, the $R a$ value and chip tool interface temperature in the turning of AISI D2. RSM based models and ANN models are implemented for prediction of the responses. The comparative result analysis between actual and predicted results has been carried out. The results obtained from ANN model for flank wear are better than RSM Model [56]. Mahammad Nizamuddin et al. (2018) have presented the research work on the performance of eco-friendly and userfriendly Karanja oil in water-based cutting fluid during orthogonal cutting of AISI 1045 steel. The further attempt has been made to identify the influence of developed and conventional cutting fluid on chip formation. Based on the findings of the study great reduction of $11 \%$ was observed in chip thickness which significantly improves tool life [57].
Gunjal and Patil (2018) have concluded in the experimental study, canola oil gives better performance. At higher cutting speed, use of traditional oil with MQL shows longer tool life than vegetable-based cutting fluids. Varying cutting speed did not show any significant impact on surface roughness, as feed rate was constant throughout the experiment. Tool wear is observed after every machining cut by virtue of average flank wear [58]. Krolczyk et al. (2019), have worked on the specific areas of interest are: Dry cutting; Minimum Quantity Lubrication/Minimum Quantity Cooling Lubrication; Cryogenic Cooling; High-Pressure Coolant and Biodegradable Vegetable Oils. The research work focuses on the improvement of machining processes with a balanced attention on the reduction of pollution generated by coolants and emulsions. The study presented in the paper will help the next generation scientists to find recent advances as well as future avenues of research on ecological aspects of machining for sustainability [59].

\subsubsection{MQL machining with nano fluid}

The literature review carried out related to MQL machining with a nano fluid system such as drilling, grinding milling and turning is as follows:

\subsubsection{Drilling}

The literature review carried out related to MQL drilling with the nano fluid system is as follows:

Heinemann et al. (2006), have concluded that deep-hole drilling is performed as the holes, drilled into plain carbon steel, had a depth of 10 times the diameter. The researcher investigated that the feasibility of dry machining as an appropriate alternative to MQL in deep-hole drilling. The research work shows that, compared to a continuous supply of the minimum quantity lubricant, a discontinuous supply brings about a significant reduction in tool life, especially in the case of heat-sensitive drills. It is also shown that dry drilling is associated with strongly accelerated tool wear for most of the twist drills tested, resulting in a significant reduction in tool life [60]. Ahmed and Kumar (2015), focused on the research study at constant doc with three different levels of cutting speed and feed rate. In the research work responses investigated by using cryogenic LN2 coolant compared with a wet coolant such as cutting temperature, thrust force, torque, and surface roughness. Chip morphology and tool wear were assessed with the changes in cryogenic LN2 coolant. The application of cryogenic coolant in the cutting zone provides good lubrication [61]. Garg et al. (2016), have carried out in the research work the analysis was based on the curve fitting. The analysis shows that among the two models, the GP models have performed better. 3-D and 2-D surface analysis was performed to validate the models. It was found that the nano fluid concentration influences in the aspect of power consumption. The drill diameter was lower, the values of torque, and the spindle speed was higher, MRR, and thrust forces, were the lowest [62]. Chata et al. (2016), studied the comparison of the performance between various lubrication conditions such as dry, MQL, flooded, and nano 
fluid MQL. The authors have studied the response parameters such as tool wear, cutting forces, and surface roughness in the drilling operation. In both MQL methods, MQL with nano-particles oil supply and MQL rate are fixed. For the nano fluid with a volumetric concentration of $1.5 \%$ in soya bean oil, the nano-particles $\left(\mathrm{Al}_{2} \mathrm{O}_{3}\right)$ of $20 \mathrm{~nm}$ in size were used. It reduces the drilling torques and thrust forces as compare to other coolant-lubrication conditions. The nano fluid MQL effectively eliminates burrs and chips to enhance the surface quality of holes [63].

\subsubsection{Grinding}

The literature review carried out related to MQL grinding with the nano fluid system is as follows:

Prabhu and Vinayagam (2011) studied the surface analysis of nano-machined AISI D2 tool steel materials which are measured using atomic force microscopy. The carbon nano tube increases the thermal conductivity of the lubricating oil and heat carrying capacity [64]. Shen Bin et al. (2009), has investigated the wheel wear and lubricating characteristics in MQL and wet grinding of cast iron. Nano fluids Al2O3 and diamond (nano particles) were applied in the MQL grinding process. Experimental results were showed that G-ratio was improved. Nano fluids showed the benefits of improving surface roughness and reducing grinding forces. From results, it was found that MQL grinding reduced the grinding temperature as compared to dry grinding [6]. Gopalakannan and Senthilvelan (2013), have prepared new fabricated metal matrix nano composite of Al 7075 reinforced with nano-particles. Electrical discharge machining was carried out to machine MMNC with the copper electrode by using a face-centered central composite design of RSM. ANOVA was applied to study the effect of process parameters and their interactions. A mathematical model has been constructed in order to estimate the machining characteristics. It was observed that pulse current was the most significant factor affecting all the three output parameters such as material removal rate, surface roughness and electrode wear rate [65]. Mao et al., (2014), concluded, MQL grinding using nano fluid showed higher grinding performance by reducing surface roughness and the grinding force in comparison with that of base fluid MQL grinding. The authors have investigated the role of nano fluid in MQL grinding process through wear and friction experiments. From the results, it was observed that nano particles, added to base fluid gives less friction and anti-wear properties. Table 3 shows Research Summary of MQL Parameters. Also it was observed that due to the addition of $\mathrm{Al}_{2} \mathrm{O}_{3}$ nano particles in deionized water decreased the friction coefficient as compared to the pure deionized water [66]. Zhang et al. (2015), have implemented nano solid particles in the cooling system of grinding process. The result calculation showed that the energy ratio coefficient of dry grinding was reached $64.3 \%$. However, the energy ratio coefficient of flood lubrication, MQL, and nano particle jet MQL were $36.8 \%, 52.1 \%$, and $41.4 \%$, respectively. The comparison of energy ratio coefficients showed that the cooling performance of CNT nano particles was satisfactory [67]. Yang et al. (2016), carried out an experimental work, a nano particle jet minimum quantity cooling grinding experiment by using hydroxyapatite, $\mathrm{SiO} 2, \mathrm{Fe} 2 \mathrm{O} 3$, carbon nano tubes nano fluids. The nano particles mass fraction was $2 \%, 4 \%$, $6 \%, 8 \%, 10 \%$ respectively. Grinding temperature during the grinding process was measured. From the results, it was observed that temperature peak of bone micro-grinding is always proportional to the mass fraction of nano fluids. The measured temperature peak shows an inversely proportional relationship with the mass fraction of nano fluid within a certain mass fraction range [68].

\subsubsection{Milling}

The literature review carried out related to MQL milling with the nanofluid system is as follows:

Sarhan et al. (2012), have performed the experimental work by mixing $\mathrm{SiO}_{2}$ nano solid particles with mineral oil having $0.2 \%$ weight concentration. After mixing of nano particles in the base fluid a sonification method was used to mix particles efficiently. From this study some response are considerable power savings, less oil consumption, and less pollution were achieved [69]. Sayuti et al. (2013), have carried out the research work, the optimum $\mathrm{SiO}_{2}$ nano lubrication parameters were used in the milling of Al6061-T6. They were investigated to achieve correct lubrication conditions for the lowest cutting force, surface roughness, and cutting temperature. The parameters include nano lubricant concentration, air carrier pressure, and nozzle angle. Taguchi optimization method was used with standard orthogonal array L16. The analyses on cutting force and surface roughness were conducted using signal-to-noise ratio. To check the statistical significance of the parameters the analysis of variance was carried out [70]. Sayuti et al. (2013), have carried out the research work; carbon onion has been used as a nano particle mixed with ordinary mineral oil. The experimental work was performed at different concentrations to investigate the cutting force reduction and the surface quality improvement of CNC end-milling machined Duralumin AL-2017-T4. From the results, it is observed that with using of carbon onion nano lubricant, the response parameters such as cutting force, and surface roughness values were reduced [71]. Mohd et al. (2013), have concluded in the research work, by introducing $\mathrm{SiO}_{2}$ nano lubricant in the cutting part produces thermal deformation and less friction leading to higher surface quality. The analysis of AL6061-T6 after machining with $\mathrm{SiO}_{2}$ nano lubricant was analyzed at different nano lubricant concentration. From the results analysis, the more use of nano lubricant concentration at $0.2 \%$ increase the growth of the thin protective film on machined surfaces. This is due to the breaking process from the rolling action of billions of nano particle between the toolchip interfaces. Therefore, it was concluded that the formations of the thin film on the surface improves the machining performance [72]. Ooi et al. (2014), have concluded that the effects of nano particle concentration, nozzle angle and air pressure are investigated to evaluate the optimum machining conditions, such as lowest cutting temperature, cutting force and surface roughness. The predicted results are determined by fuzzy logic [73]. Pham et al. (2014) focused on nano particle-enhanced cutting fluids in the research study. They found that very little work has 
Table 3. Research summary of MQL parameters.

\begin{tabular}{|c|c|c|c|c|c|}
\hline Author & Cutting fluid & Work piece material & $\begin{array}{l}\text { MQL- Air } \\
\text { fluid } \\
\text { pressure (bar) }\end{array}$ & $\begin{array}{l}\text { MQL }- \text { Flow } \\
\text { rate }(\mathrm{ml} / \mathrm{h})\end{array}$ & Reference \\
\hline Dhar et al. (2006) & Not mentioned & Alloy Steel AISI- 1040 & 7 & 60 & {$[3]$} \\
\hline Dhar et al. (2007) & Mobil cut 102 & Alloy Steel AISI- 1040 & - & 200 & {$[4]$} \\
\hline Khan et al. (2009) & Vegetable oil & Alloy Steel AISI 9310 & 6 & 100 & {$[23]$} \\
\hline Tawakoli et al. (2010) & Mineral oil & Harden Steel 100Cr6 & $2,3,4,7$ & $20,50,100$ & [91] \\
\hline Barczak et al. (2011) & Pure synthetic oil & EN8, M2, EN31 & 4 & 33 & {$[31]$} \\
\hline Emami et al. (2013) & Mineral oil & $\begin{array}{l}\mathrm{Al}_{2} \mathrm{O}_{3} \text { Engineering } \\
\text { Ceramic }\end{array}$ & $\begin{array}{l}\text { Not } \\
\text { mentioned }\end{array}$ & $25-400$ & {$[92]$} \\
\hline Balan et al. (2013) & MQL oil & Inconel 751 & $2,4,6$ & $60,80,100$ & {$[34]$} \\
\hline Mao et al. (2013) & Nano fluid & AISI 52100 & $2,4,6,8$ & 60 & {$[66]$} \\
\hline Saini et al. (2014) & Mineral oil & Alloy Steel AISI- 4340 & 4 & 300 & [81] \\
\hline
\end{tabular}

been carried out on nano fluids and examined performances of ionic liquids as lubricants in the micro milling process. They have suggested that use of higher viscosity ionic coolant provided good machined surface characteristics as compared with conventional lubrication conditions [74]. Rahmati et al. (2014), have performed the research work; the optimum $\mathrm{MoS}_{2}$ nano lubrication factors in Al6061-T6 milling to acquire the lower cutting force, surface roughness, cutting temperature are determined. In this study, the parameters were selected nano lubricant concentration, nozzle orientation, and air carrier pressure. The cutting force, surface roughness was analyzed signal/noise ratio. The analysis of variance is carried out for achieving optimum conditions and to determine the process parameters are statistically significant was carried out [75].

\subsubsection{Turning}

The literature review carried out related to MQL turning with the nano fluid system is as follows:

Saidura et al. (2011), have carried out, comprehensive literature on the applications and challenges of nano fluids have been compiled and reviewed. The application of nano fluids in cooling of a heat exchanging devices, solar water heating, cooling of transformer oil, engine cooling, cooling of electronics, cooling in machining have been reviewed and presented. However, less barriers and problems that has been identified in the review paper and addressed neatly [76]. Chan et al. (2013), have performed an experimental study on the effect of the low viscosity cutting fluid with nano-droplets in ultra-precision turning. The conventional flood method in which cooling enhancement is improved by adding nano-metric particles. Instead, the NDCFs are created by atomization of the cutting fluid that circulates in a closed- loop treatment device. The atomization process is found to minimize the viscosity of the NDCF significantly by the formation of nano-droplets. The minimized viscosity of the NDCFs could be increased by diluting them with water [77]. Roy and Ghosh (2013) have analyzed the effect of process parameters during high speed turning of AISI steel with nano fluid ( 1 vol. \% MWCNT and 3 vol. $\%$ alumina) and small quantity lubrication system. From result analysis, it is found that due to the use of MWCNT there is a reduction in cutting forces [78]. Amrita et al. (2014), have investigated the usage of and nano- molybdenum disulfide, nano-graphite, oil-based cutting fluids in MQL application. The initial work was to prepare a cutting fluid by adding $0.3 \mathrm{wt} \%$ of nano particles. The dispersion and stability of nano particles in the base fluid were verified. While performing turning operation under constant cutting conditions, the prepared cutting fluids with nano particles were applied at a flow rate of $10 \mathrm{ml}$ per minute. Performance of cutting fluids was examined by measuring surface roughness, cutting forces, tool wear and cutting temperature for each turn [79]. Sayuti et al. (2014) evaluated the performance of $\mathrm{SiO}_{2}$ nano fluid in turning of hardened steel AISI 4140 using MQL. This research work was investigating on the new and novel uses of $\mathrm{SiO}_{2}$ nano-lubricant by conducting analysis on tool wear and surface roughness using fuzzy logic. Also, response analysis was carried out determining which process parameters were statistically significant. From experimental work, it was found that surface integrity and tool wear were observed with $0.5 \%$ wt $\mathrm{SiO}_{2}$ concentration, $30^{\circ}$ nozzle angles, and low air pressure [80]. Saini et al. (2014), have investigated in the research work, the Minimum Quantity Lubrication machining performance was found to be better than dry machining. The influence of approach angle, cutting speed, feed rate, and depth of cut has been on cutting forces and tool tip temperature has been experimentally investigated. In this study work, the use of nano fluid reduced the cutting forces up to $17.07 \%$ [81]. Krajnik et al. (2016) have concluded in the research work how recent nanotechnology developments support and needed for the production of the new product and industrial applications. Authors have designed and fabricated a nano particle-based cooling-lubricating fluid, for vegetable-based fluids. Also, such a cooling system has been developed for integration into material processing technologies. They have shown that tribology property of nano fluids reduces the friction between chip interfaces and tool [82]. Hegab et al. (2018) have performed the research study to improve the cooling efficiency of MQL during machining of titanium alloys with nano-additives. The aim 
of the research work was to find out the influence of dispersed MWCNT into base fluid under MQL mode. It was found that two \% MWCNT nano fluid reduced the power consumption by eleven $\%$. The same concentration of nano fluid also reduced the flank wear by $45 \%$ [83]. Das et al. (2019), have found that, vegitable oil based nanofluid enriched cutting fluids for machining. Also extensive research has been carried out to replace conventional cutting fluids by nanofluids. The research study investigated the cutting performance and comparative assessment towards machinability improvement during hard turning of high-strength-low-alloy AISI 4340 steel using four different compositions of nanofluids by minimum quantity lubrication technique. surface integrity, cutting force, tool wear, microhardness, residual stress, and chip morphology are considered as technological performance characteristics to evaluate the machinability of hardened AISI 4340 steel [84]. Mohammad et al. (2020), have discussed the behaviour of various thermophysical properties of $\mathrm{CuO}$ water-based nanofluids. Different experimental and theoretical studies are carried out to investigate each property of $\mathrm{CuO} /$ water in terms of thermal and fluid mechanics. Researchers concluded that, thermal conductivity increases with large particle size, whereas viscosity increases with small particle size. The Nusselt number depends on the flow rate and volume fraction of nano particles. The causes for these behaviour were discussed. The magnitude of heat transfer rate is influenced by the use of $\mathrm{CuO}$ /water nano fluids. The use of $\mathrm{CuO} /$ water nano fluids has many issues and challenges that need to be classified through additional studies [85].

\section{Importance/role of nano particles}

Nano particles having higher heat carrying capacity. Nano fluid is a new class of fluids engineered by dispersing nanometer-size solid particles into base fluids such as water, ethylene glycol, lubrication oils and synthetic oil. Research shows thermal conductivity and convection heat transfer coefficient of the fluid enhanced by nano particles. Tribology research showes lubricating oil with nano particle additives improves Load carrying capacity, Anti-wear and Friction reduction etc. Novel properties of carbn nano tubes are extra ordinary strength, unique electrical properties, and efficient conductor of heat. A Carbon Nanotube having tube-shaped material shape, which is made of carbon. Carbon Nanotubes typically have diameters ranging from 1 to $50 \mathrm{~nm}$. The recent advancements have made the nanotubes much longer and measured in centimeters. The discovery of Carbon Nanotubes (CNTs) in 1991 opened up a new era in materials science. CNTs are at least 100 times stronger than steel and one-sixth as heavy. Therefore, nano tube fibers could strengthen almost any material. CNTs are unique because the bonding between the atoms is very strong [6].

\subsection{Multi-walled carbon nano tubes (MWCNT)}

Multi-walled carbon nanotubes range from one outer and one inner tube to as many as 100 tubes or more. Currently,
Table 4. Thermal conductivities of different nano-particles.

\begin{tabular}{ll}
\hline Nano particles & $\begin{array}{l}\text { Thermal conductivity } \\
(\mathrm{W} / \mathrm{m}-\mathrm{K})\end{array}$ \\
\hline Aluminum oxide $\left(\mathrm{Al}_{2} \mathrm{O}_{3}\right)$ & 36 \\
Diamond $(\mathrm{C})$ & 2300 \\
Carbon nanotube $(\mathrm{CNT})$ & 3000 \\
Copper $(\mathrm{Cu})$ & 401 \\
Graphite & 750 \\
Gold & 310 \\
Silver $(\mathrm{Ag})$ & 697 \\
Aluminum $(\mathrm{Au})$ & 518 \\
\hline
\end{tabular}

Table 5. Specifications of MWCNT's.

\begin{tabular}{ll}
\hline Parameter & Value \\
\hline Outer dia. $(\mathrm{Nm})$ & $20-30$ \\
Inner dia. $(\mathrm{Nm})$ & $5-10$ \\
Ash. $(\mathrm{Wt} \%)$ & $<1.5$ \\
Purity $(\mathrm{Wt} \%)$ & $>95$ \\
Length $(\mathrm{Nm})$ & $10-30$ \\
Bulk density $\left(\mathrm{g} / \mathrm{cm}^{3}\right)$ & 0.28 \\
True density $\left(\mathrm{g} / \mathrm{cm}^{3}\right)$ & 2.1 \\
\hline
\end{tabular}

the most popular use for carbon nano tubes is in structural reinforcement. Carbon nano tubes are unique and thermally conductive along their length. The semiconducting properties of CNTs promote for the generation of computer chips. Other applications of CNTs are as chemical carriers for pharmaceutical applications [6]. Table 4 shows the different nano particles with their thermal conductivities and Table 5 shows specifications of MWCNT's.

To improve the surface characteristics from the micro level to nano level, nanofluid (Multi-walled Nano Tube) is useful in the machining process. The improved heat transfer and tribological properties of nanofluid can provide better cooling and lubricating in the MQL machining process and make it production easier.

\section{Development/preparation of nano fluid}

Nano fluid is a new class of fluids which are prepared by dispersing nano solid particles into base fluids such as water, ethylene glycol, lubrication oils, and synthetic oil. The steps involved in preparation of nano fluid. As per the calculation, one-liter base fluid as synthetic cutting oil, $5 \mathrm{gm}$ Sodium Dodecyl Sulfate (SDS) and $2.5 \mathrm{~g}$ Gum Arabic (GA) was taken. Such a mixture was stirred for two hours on a magnetic stirrer.

- In a prepared base fluid, 2.1 g MWCNT's should be added and stirred for $40 \mathrm{~min}$ on the overhead stirrer.

- Now after stirring, sonicate the mixture for about one hour in the ultrasonication bath until a homogeneous suspension was achieved during the sonication. It is 


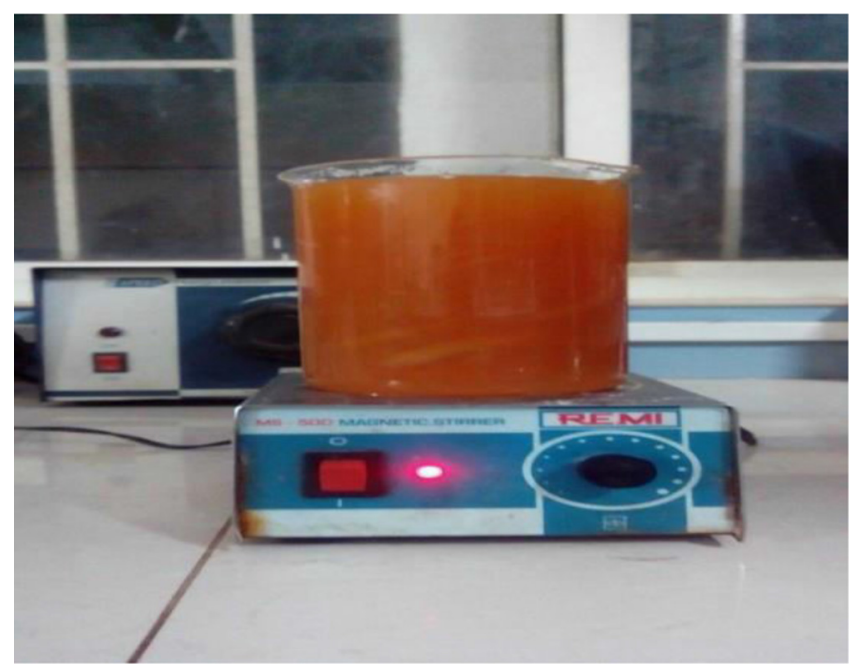

Fig. 10. Magnetic Stirrer (Patole and Kulkarni).

observed that the bubble formed and collapsed. It is conjectured that the resulting shock from this cavitations process (collapsing bubbles) breaks up the nanotube agglomerates. However, sonication generates heat which results in an increase in nanofluid temperature. To avoid the variation of temperature, the cooling system is employed. The role of the cooling system is to maintain the temperature at about $25^{\circ} \mathrm{C}$ so that prepared mixtures remain stable for weeks. The sample preparation set up is shown in Figures 10 and 11.

\subsection{Calculation of MWCNT}

The Multi-walled carbon nano tube particle is mixed with cutting fluid. The cutting fluid such as ethylene glycol in the proportion of the MWCNT is mixed in the concentration of $0.2 \%$. The nano cutting fluid is prepared for $2 \mathrm{~L}$. The mass of the MWCNT nano particle required for the preparation of nano fluid is calculated as follows:

Density of $\mathrm{MWCNT}=2100 \mathrm{~kg} / \mathrm{m}^{3}$, One liter $=$ $(1 / 1000) \mathrm{m}^{3}$,

Therefore, Mass $=$ Density $\times$ Volume,

for $1 \mathrm{~L}$ the mass of MWCNT required is, Mass $=$ $(2100 \times 1) / 1000=2.1 \mathrm{~kg}$ at $0.1 \%$ concentration mass $=$ $(2.1 \times 0.1 \times 1000) / 100=2.1 \mathrm{~g}$.

At $0.2 \%$ concentration mass $=(2.1 \times 0.2 \times 1000) /$ $100=4.2 \mathrm{~g}$. For $2 \mathrm{~L}$ the mass of $\mathrm{MWCNT}=4.2 \times 2=8.4 \mathrm{~g}$

The mass of the MWCNT required for the preparation of nano fluid is $8.4 \mathrm{~g}$ This nano particle is mixed with the cutting fluid using 'Ultrasonic Vibrator' in the Nano Science Laboratory. Then the nano cutting fluid is used as the coolant for the turning operation $[93,94]$.

\section{MQL with nano fluid experimental setup}

Figure 12 shows a schematic sketch of the MQL with nano fluid experimental setup.

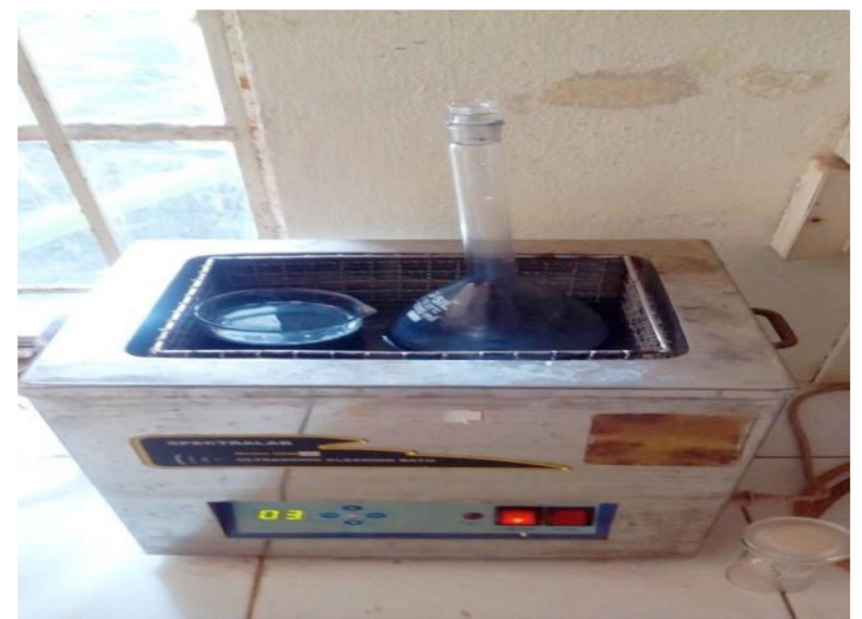

Fig. 11. Ultrasonic Vibrator (Patole and Kulkarni).

The list of equipment's in MQL with nano fluid experimental setup is listed here.

- Computer Numerical Control (CNC) Lathe machine

- MQL with nano fluid cooling system

- Kistler Tool Dynamometer

- Display Unit

The material to be machined is hold firmly within the chuck. Kistler dynamometer is used for material machining to measure the forces involved in the machining. The tool feeds perpendicular to the material to generate a cutting force and a normal (or thrust) force. The tool's direction of motion eliminates the radial force or brings it down to near zero. This allows the use of a tailstock to support the center of the work piece. This set-up is commonly done with high tensile strength materials such as steel, sacrificing long duration runs. The jaws may be insulated to protect the work. Kistler Dynamometer is connected with $\mathrm{A} / \mathrm{D}$ converter $[95,96]$.

\section{Conclusions}

It is seen that different researchers have proposed different coolant and cooling systems such as conventional flood system, jet spray system, near dry system, MQL system etc. for machining. The conventional flood systems are practically accepted by the metal cutting industries. However, it has certain inherent disadvantages such as unaffordable cost, the requirement of skilled manpower, limited turning performance. On this background, MQL with nano fluid cooling technique is more suitable for the low volume and better turning characteristics. There is a scope for use of MQL with nano fluid in metal cutting industries during machining operation to improve the turning characteristics.

From the literature survey and review the following findings are drawn:

- Majority of the metal cutting industries are still using the conventional flood system for the machining of the work pieces. Also it is reported that about $16-20 \%$ cost is involved in lubrication system. 


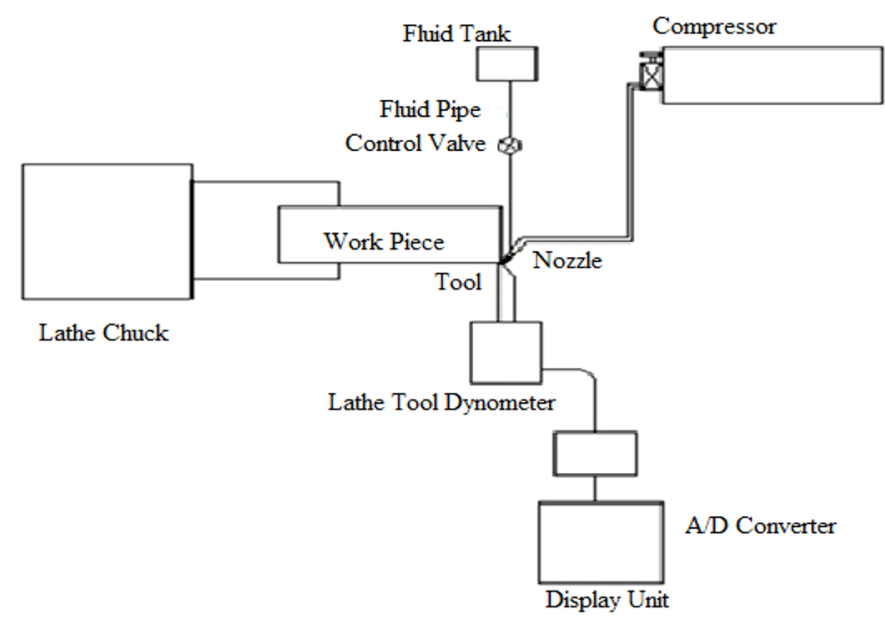

Fig. 12. Schematic diagram of MQL with nano fluid experimental setup (Patole and Kulkarni).

- Very few industries and modern workshops are finding the application of minimum quantity lubrication with conventional fluid for small scale industries because of the unaffordable initial cost.

- The conventional cutting fluid application fails to penetrate the chip-tool interface and thus cannot remove heat effectively. On the other hand in MQL the heat removal can be takes place and it also provides sufficient lubrication to prevent the generation of heat.

- The application of MQL is an alternative for conventional flood system.

- The cooling and lubrication system consultants and the academicians raised the need of MQL with nano fluid during the machining process.

\section{The scope for future research work}

This research paper has presented a brief review of important published researches in the application of nanofluid-based cutting fluids with the help of MQL technique during different machining processes, such as, grinding, drilling, milling and turning, etc. Some of the researchers shown that nano fluids plays an important role in cooling applications in manufacturing industries, transportation, energy, and electronics, etc. But developments in new technologies such as metal cutting operations i.e. turning, drilling, grinding etc., microelectronic devices, higher power output engines, continuously increase the thermal loads, which require advances in cooling capacity. Therefore, there is a strong need for new and promoting faster heat transfer nano fluids to achieve better cooling performance.

A few researchers found that, MQL is suitable for softer material and has limitations with regard to harder materials. Therefore, it is required to resolve this argument by studying the effectiveness of MQL with nano fluid on the material during machining process.

\section{References}

1. S. Narana Rao, B.S. Satyanarayana, Experimental estimation of tool wear and cutting temperatures in MQL using cutting fluids with CNT inclusion, Int. J. Ind. Eng. Sci. Technol. (2011)

2. H. Suhil Adheil, N. Ismail, Optimization of cutting parameters of turning operations by using geometric programming, Am. J. Eng. Appl. Sci. 3 (2010) 102-108

3. N.R. Dhar, M. Kamruzzaman, M. Ahmed, Effect of minimum quantity lubrication on tool wear and surface roughness in turning AISI 4340 steel, J. Mater. Process. Technol. 172 (2006) 299-304

4. N.R. Dhar, S. Islam, M. Kamruzzaman, Effect of minimum quantity lubrication on tool wear, surface roughness and dimensional deviation in turning AISI-4340 Steel, G. U. J. Sci. 20 (2007) 23-32

5. B. Tasdelen, H. Thordenberg, D. Olofsson, An experimental investigation on contact length during MQL machining, J. Mater. Process. Technol. 203 (2008) 221-231

6. S. Bin, A.J. Shih, S.C. Tung, Application of nano fluids in minimum quantity lubrication grinding, J. Tribol. Lubr. Technol. 51 (2009) 730-737

7. H. Huang, Y.C. Liu, Experimental investigations of machining characteristics and removal mechanisms of advanced ceramics in high speed deep grinding, Int. J. Mach. Tools Manuf. 43 (2003) 811-823

8. G. Mauvoisin, O. Bartier, R.E. Abdi, A. Nayebi, Influence of material properties on the drilling thrust to hardness ratio, Int. J. Mach. Tools Manuf. 43 (2003) 825-832

9. J. Xie, M.J. Luo, K.K. Wu, L.F. Yang, D.H. Li, Experimental study on cutting temperature and cutting force in dry turning of titanium alloy using a non-coated micro-grooved tool, Int. J. Mach. Tools Manuf. 73 (2013) 25-36

10. A. Devillez, F. Schneider, S. Dominiak, D. Dudzinski, D. Larrouquere, Cutting forces and wear in dry machining of Inconel 718 with coated carbide tools, J. Wear 262 (2007) 931-942

11. K.-M. Li, S.Y. Liang, Modeling of cutting forces in near dry machining under tool wear effect, Int. J. Mach. Tools Manuf. (2007) 1292-1301

12. P.S. Sripathi, Investigation into the effects of tool geometry and metal working fluids on tool forces and tool surfaces during orthogonal tube turning of aluminum 6061 alloy. M.S. thesis submitted to Auburn University, Alabama, December 18, (2009)

13. M. Nalbant, H. Gokkaya, G. Sur, Application of Taguchi method in the optimization of cutting parameters for surface roughness in turning, J. Mater. Des. 28 (2013) 1379-1385

14. I.S. Jawahir, E. Brinksmeier, R.M. Saoubi, D.K. Aspinwall, J.C. Outeiro, D. Meyer, D. Umbrello, A.D. Jayal, Surface integrity in material removal processes: recent advances, CIRP Ann.- Manuf. Technol. 60 (2011) 603-626

15. S.A. Lawal, I.A. Choudhury, Y. Nukman, A critical assessment of lubrication techniques in machining processes: a case for minimum quantity lubrication using vegetable oilbased lubricant, J. Clean. Prod. 41 (2013) 210-221

16. S. Varun, P.M. Pandey, Comparative study of turning of 4340 hardened steel with hybrid textured self lubricating cutting inserts, Mater. Manuf. Process. (2015)

17. P. Alokesh, G. Little fair, Machining of titanium alloy (Ti-6al-4v) theory to application, J. Mach. Sci. Technol. 19 (2015) 1-49 
18. S.A. Kumar, S. Bidyadhar, Experimental investigation on machinability aspects in finish hard turning of AISI 4340 steel using uncoated and multilayer coated carbide inserts, Measurement 45 (2012) 2153-2165

19. D. Zhu, X. Zhang, H. Ding, Tool wear characteristics in machining of nickel-based super alloys, Int. J. Mach. Tools Manuf. 64 (2013) 60-77

20. S. Debnath, M.M. Reddy, Q.S. Yi, Environmental friendly cutting fluids and cooling techniques in machining: a review, J. Clean. Prod. 83 (2014) 33-47

21. K. Simunovic, G. Simunovic, T. Saric, Single and multiple goal optimization of structural steel face milling process considering different methods of cooling/lubricating, J. Clean. Prod. 94 (2015) 321-329

22. J.F. Kelly, M.G. Cotterell, Minimal lubrication machining of aluminum alloys, J. Mater. Process. Technol. 120 (2002) 337-334

23. M.M.A. Khan, M.A.H. Mithua, N.R. Dharb, Effects of minimum quantity lubrication on turning AISI 9310 alloy steel using vegetable oil based cutting fluid, J. Mater. Process. Technol. 209 (2009) 5573-5583

24. S. Sharma Vishal, D. Manu, N.M. Suri, Cooling techniques for improved productivity in turning, J. Mater. Process. Technol. 49 (2009) 435-453

25. T. Obikwa, Y. Asano, Y. Kamata, Computer fluid dynamics analysis for efficient spraying of oil mist in finish-turning of Inconel 718, Int. J. Mach. Tools Manuf. 49 (2009) 970-978

26. Md.A. Hasib, A. Al-farukh, N. Ahmed, Mist application of cutting fluid, Int. J. Mech. Mechatron. Eng. 10 (2010) 10-11

27. K.Y. Hwang, C.I. Lee, Surface roughness and cutting force prediction in MQL and wet turning process of ASSI 1045 using design of experiments, Int. J. Mech. Sci. Technol. 24 (2010) 1669-1676

28. C.M. Huseyin, B. Ozcelik, E. Kurama, E. Demirbas, Evaluation of vegetable based cutting fluids with extreme pressure and cutting parameters in turning of AISI 304L by Taguchi method, J. Clean. Prod. 19 (2011) 2049-2056

29. Y. Kaynak, H.E. Karac, R.D. Noeb, I.S. Jawahir, Tool-wear analysis in cryogenic machining of NITI shape memory alloys: a comparison of tool-wear performance with dry and MQL machining, J. Wear 306 (2013) 51-63

30. S.M. Yuan, L.T. Yuan, W.D. Liu, Effect of cooling air temperature on cryogenic machining of Ti-6Al-4V alloy, J. Mater. Process. Technol. 211 (2011) 356-362

31. L.M. Barczak, A.D. Batako, Application of minimum quantity lubrication in grinding, J. Mater. Manuf. Process. 27 (2012) 406-411

32. P. Zeilmann Rodrigo, G.L. Nicola, T. Vacaro, C.R. Teixeira, R. Heiler, Implications of the reduction of cutting fluid in drilling AISIP20 steel with carbide tools, Int. J. Adv. Manuf. Technol. 58 (2012) 431-441

33. H. Patil Deepak Kumar, Investigation on finish turning of AISI 4340 steel in different cutting environments by CBN insert, Int. J. Eng. Sci. Technol. 10 (2011)

34. A.S.S. Balan, L. Vijayaraghavan, R. Krishnamurthy, Minimum quantity lubricated grinding of Inconel 751 alloy, J. Mater. Manuf. Process. 28 (2013) 430-435

35. C. Nath, S.G. Kapoor, A.K. Srivastav, Effect of fluid concentration in titanium machining with an AtomizationBased Cutting Fluid (ACF) spray system, Int. J. Manuf. Process. 15 (2013) 419-425
36. M. Cong, H. Zou, Y. Huang, Y. Li, Z. Zhou, Analysis of heat transfer coefficient on workpiece surface during minimum quantity lubricant grinding, Int. J. Adv. Manuf. Technol. 66 (2013) 363-370

37. C.S. Rakurty, P.I. Varela, A.K. Balaji, Effects of targeted minimum quantity fluid application on surface integrity, Procedia CIRP 8 (2013) 462-468

38. S.A. Lawal, I. Choudhury, A.Y. Nukman, Application of vegetable oil-based metal working fluids in machining ferrous metals, Int. J. Mach. Tools Manuf. 52 (2012) 1-12

39. T. Minton, S. Ghani, F. Sammler, R. Bateman, P. Fürstmann, M. Roeder, Temperature of internally-cooled diamond-coated tools for dry-cutting titanium, Int. J. Mach. Tools Manuf. 75 (2013) 27-35

40. S.K. Komini, K.S. Praveen, B. Raja, P. Damodharan, Measurement of thermal conductivity of fluid using single and dual wire transient techniques, J. Meas. 46 (2013) $2746-2752$

41. Md A. Imran, B. Kotiveerachary, Study of the effect of minimum quantity lubrication on surface roughness of Incoloy 800 during turning operation, Int. J. Curr. Eng. Technol. (2013) 439-448.

42. S. Dinesh, M.K. Sinha, S. Ghosh, P. Venkateswara Rao, An effective method to determine the optimum parameters for minimum quantity lubrication grinding, In: 5th International and 26th All India Manufacturing Technology, Design and Research Conference (AIMTDR 2014) December 12th-14th, 2014, IIT Guwahati, Assam, India, 2014

43. P.C. Priarone, M. Robiglio, L. Settineri, V. Tebaldo, Milling and turning of titanium aluminides by using minimum quantity lubrication, Procedia CIRP 24 (2014) 62-67

44. W. Sheng, C. Li, D. Zhang, D. Jia, Y. Zhang, Modeling the operation of a common grinding wheel with nanoparticle jet flow minimal quantity lubrication, Int. J. Adv. Manuf. Technol. (2014)

45. D.A. Stephenson, S.J. Skerlos, A.S. King, Rough turning Inconel 750 with supercritical Co2- based minimum quantity lubrication, J. Mater. Process. Technol. 214 (2014) 673-680

46. N. Banerjee, A. Sharma, Identification of a friction model for minimum quantity lubrication machining, J. Clean. Prod. 83 (2014) 437-443

47. G. Rotella, O.W. Dillon, D. Umbrell, L. Settineri, I.S. Jawahir, The effects of cooling conditions on surface integrity in machining of Ti6Al4V alloy, Int. J. Adv. Manuf. Technol. 71 (2014) 47-55

48. S. Amini, H. Khakbaz, A. Barani, Improvement of near-dry machining and it's effect on tool wear in turning of AISI 4142, J. Mater. Manuf. Process. 30 (2015) 241-247

49. F. Domnita, Numerical and experimental approach of cutting temperatures to green turning of $42 \mathrm{CrMo} 4$ steel, J. Mater. Manuf. Process. (2015)

50. M.K. Gupta, P.K. Sood, S. Sharma Vishal, Machining parameters optimization of titanium alloy using response surface methodology and particle swarm optimization under minimum quantity lubrication environment, J. Mater. Manuf. Process. (2015)

51. A.D.L. Batako, V. Tsiakoumis, An experimental investigation into resonance dry grinding of hardened steel and nickel alloys with element of MQL, Int. J. Adv. Manuf. Technol. 77 (2015) 1-4 
52. Chetan, S. Ghosh, P.V. Rao, Application of sustainable techniques in metal cutting for enhanced machinability: a review, J. Clean. Prod. 100 (2015) 17-34

53. M. Sarıkaya, A. Güllü, Multi-response optimization of minimum quantity lubrication parameters using Taguchibased grey relational analysis in turning of difficult-to-cut alloy Haynes 25, J. Clean. Prod. 91 (2015) 347-357

54. H. Hamed, M.H. Sadeghi, H. Rezaei, A. Rasti, Experimental study of cutting force, microhardness, surface roughness, and burr size on micro milling of Ti6Al4V in minimum quantity lubrication, J. Mater. Manuf. Process. (2016)

55. N. Verma, K. Manoj Kumar, A. Ghosh, Characteristics of aerosol produced by an internal-mix nozzle and its influence on force, residual stress and surface finish in SQCL grinding, J. Mater. Process. Technol. 240 (2017) 223-232

56. R. Kumar, A. Kumar, S.R. Kumar, D. Amlana, P. Purna, C. Mishra, Modelling of flank wear, surface roughness and cutting temperature in sustainable hard turning of AISID2 steel, Procedia Manuf. 20 (2018) 406-413

57. M. Yacoub, A. Shdaifat, R. Zulkifli, K. Sopian, A.A. Salih, Thermal and hydraulic performance of $\mathrm{CuO}$ /water nanofluids: a review, Micromachines 11 (2020) 416

58. U. Gunjal Shrikant, G. Patil Nilesh, Experimental investigations into turning of hardened AISI 4340 steel using vegetable based cutting fluids under minimum quantity lubrication, Procedia Manuf. 20 (2018) 18-23

59. G.M. Krolczyk, R.W. Marudaz, J.B. Krolczyk, S. Wojciechowski, M. Mia, P. Nieslony, G. Budzik, Ecological trends in machining as a key factor in sustainable production: a review, J. Clean. Prod. 218 (2019) 601-615

60. R. Heinemann, S. Hinduja, G. Barrow, G. Petuelli, Effect of MQL on the tool life of small twist drills in deep-hole drilling, Int. J. Mach. Tools Manuf. 46 (2006) 1-6

61. A.L. Shakeel, M. Pradeep Kumar, Cryogenic drilling of Ti-6Al-4V alloy under liquid nitrogen cooling, J. Mater. Manuf. Process. (2015) 1-9

62. G. Akhil, S. Sarma, B.N. Panda, J. Zhang, L. Gao, Study of effect of nano fluid concentration on response characteristics of machining process for cleaner production, J. Clean. Prod. 135 (2016) 476-489

63. C.S. Singh, A. Pal, T. Singh, Performance evaluation of aluminium 6063 drilling under the influence of nano fluid minimum quantity lubrication, J. Clean. Prod. 137 (2016) 537-545

64. S. Prabhu, B.K. Vinayagam, Fractal dimensional surface analysis of AISID2 tool steel material with nano fluids in grinding process using atomic force microscopy, J. Braz. Soc. Mech. Sci. Eng. 4 (2011) 466

65. S. Gopalakannan, T. Senthilvelan, Application of response surface method on machining of Al-Sic nano-composites, J. Meas. 46 (2013) 2705-2715

66. M. Cong, Y. Huang, X. Zhou, H. Gan, J. Zhang, Z. Zhou, The tribological properties of nanofluid used in minimum quantity lubrication grinding, Int. J. Adv. Manuf. Technol. 71 (2014) 1221-1228

67. Z. Dongkun, C. Li, Y. Zhang, D. Jia, X. Zhang, Experimental research on the energy ratio coefficient and specific grinding energy in nano particle jet MQL grinding, Int. J. Adv. Manuf. Technol. 78 (2015) 1275-1288

68. Y. Min, C. Li, Y. Zhang, Y. Wang, B. Li, Y. Hou, Experimental research on micro scale grinding temperature under different nano particle jet minimum quantity cooling, J. Mater. Manuf. Process. (2016)
69. A.D. Sarhan Ahmed, M. Sayuti, M. Hamdi, Reduction of power and lubricant oil consumption in milling process using a New $\mathrm{SiO}_{2}$ nano lubrication system, Int. J. Adv. Manuf. Technol. 63 (2012) 505-512

70. M. Sayuti, A.A.D. Sarhan, M. Hamdi, An investigation of optimum $\mathrm{SiO}_{2}$ nano lubrication parameters in end milling of aerospace Al6061-T6 alloy, Int. J. Adv. Manuf. Technol. 67 (2013) 833-849

71. M. Sayuti, A.A.D. Sarhan, T. Tanaka, M. Hamdi, Y. Saito, Cutting force reduction and surface quality improvement in machining of aerospace duralumin AL-2017-T4 using carbon onion nano lubrication system, Int. J. Adv. Manuf. Technol. 65 (2013) 1493-1500

72. M. Sayuti, A.A.D. Sarhan, F. Salem, Novel uses of $\mathrm{SiO}_{2}$ nanolubrication system in hard turning process of hardened steel AISI4140 for less tool wear, surface roughness and oil consumption, J. Clean. Prod. 67 (2014) 265-276

73. M.E. Ooi, M. Sayuti, A.A.D. Sarhan, Fuzzy logic-based approach to investigate the novel uses of nano suspended lubrication in precise machining of aerospace $\mathrm{AL}$ tempered grade 6061, J. Clean. Prod. (2014) 1-10

74. M.Q. Pham, H.S. Yoon, V. Khare, S.H. Ahn, Evaluation of ionic liquids as lubricants in micro milling-process capability and sustainability, J. Clean. Prod. 76 (2014) 167-173

75. R. Bizhan, A.A.D. Sarhan, M. Sayuti, Investigating the optimum molybdenum disulfide (Mos2) nanolubrication parameters in CNC milling of AL6061-T6 alloy, Int. J. Adv. Manuf. Technol. 70 (2014) 1143-1155

76. R. Saidura, K.Y. Leongb, H.A. Mohammadc, A review on applications and challenges of nanofluids, Renew. Sustain. Energy Rev. 15 (2011) 1646-1668

77. C.Y. Chan, W.B. Lee, H. Wang, Enhancement of surface finish using water-miscible nano-cutting fluid in ultraprecision turning, Int. J. Mach. Tools Manuf. 73 (2013) $62-70$

78. S. Roy, A. Ghosh, High speed turning of AISI 4140 steel using nano fluid through twin jet SQL system. In: $A S M E$ International Manufacturing Science and Engineering Conference, pp. 10-14, 2013

79. M. Amrita, S.A. Shariqa, Experimental investigation on application of emulsifier oil based nano cutting fluids in metal cutting process, Procedia Eng. 97 (Experimental Investigation on Application of Emulsifier Oil based Nano Cutting Fluids in Metal Cutting Process (2014) 115-124

80. M. Sayuti, A.A.D. Sarhan, F. Salem, Novel uses of $\mathrm{SiO}_{2}$ nanolubrication system in hard turning process of hardened steel AISI 4140 for less tool wear, surface roughness and oil consumption, J. Clean. Prod. 67 (2014) 265-276

81. A. Saini, S. Dhiman, R. Sharma, S. Setia, Experimental estimation and optimization of process parameters under minimum quantity lubrication and dry turning of AISI-4340 with different carbide inserts, J. Mech. Sci. Technol. 28 (2014) 2307-2318

82. P. Krajnik, A. Rashid, F. Pu_savec, M. Remskar, A. Yui, N. Nikkam, M.S. Toprak, Transitioning to sustainable production-part III: developments and possibilities for integration of nanotechnology into material processing technologies, J. Clean. Prod. 112 (2016) 1156-1164

83. H. Hegab, U. Umer, I. Deiab, H. Kishawy, Performance evaluation of Ti-6Al-4V machining using nano-cutting fluids under minimum quantity lubrication, Int. J. Adv. Manuf. Technol. 95 (2018) 4229-4241 
84. D. Anshuman, P.S. Kumar, D.S. Ranjan, Performance comparison of vegetable oil based nanofluids towards machinability improvement in hard turning of HSLA steel using minimum quantity lubrication, Mech. Ind. 20 (2019) 506

85. N. Mahammad, M. Agrawal Sachin, P. Nilesh, The effect of karanja based soluble cutting fluid on chips formation in orthogonal cutting process of AISI 1045 steel, Procedia Manuf. 20 (2020) 12-17

86. A.S. Varadarajan, P.K. Philip, B. Ramamoorthy, Investigations on Hard Turning with Minimal Cutting Fluid Application (HTMF) and it's comparison with dry and wet turning, Int. J. Mach. Tools Manuf. 42 (2002) 193-200

87. A.N.M. Khalila, M.A. Alib, A.I. Azmic, Effect of $\mathrm{Al}_{2} \mathrm{O}_{3}$ nano lubricant with SDBS on tool wear during turning process of AISI 1050 with minimal quantity lubricant. In: 2nd International Materials, Industrial, and Manufacturing Engineering Conference, MIMEC2015, 4-6 February 2015, Bali Indonesia

88. M.A.M. Ali, A.N.M. Khalil, A.I. Azmi, H.M. Salleh, Optimization of cutting parameters for surface roughness under MQL, using Al2O3 nano lubricant, during turning of Inconel 718, IOP Conf. Ser. Mater. Sci. Eng. 226 (2017) 1-7

89. Y. Muthusamy, K. Kadirgama, M.M. Rahman, D. Ramasamy, K.V. Sharma, Wear Analysis when machining AISI 304 with ethylene glycol $/ \mathrm{TIO}_{2}$ nano particle-based coolant, Int. J. Adv. Manuf. Technol. 82 (2016) 327-340
90. K. Kadirgama, K. Anamalai, K. Ramachandran, D. Ramasamy, M. Samykano, A. Kottasamy, S. Lingenthiran, M.M. Rahman, Thermal analysis of SUS 304 stainless steel using ethylene glycol/nano cellulose-based nanofluid coolant, Int. J. Adv. Manuf. Technol. (2018)

91. T. Tawakoli, M.J. Hadad, M.H. Sadeghi, Influence of oil mist parameters on minimum quantity lubrication-MQL grinding process, Int. J. Mach. Tools Manuf. 50 (2010) 521-531

92. M. Emami, M.H. Sadeghi, A.A.D. Sarhan, Investigating the effects of liquid atomization and delivery parameters of minimum quantity lubrication on the grinding process of $\mathrm{Al}_{2} \mathrm{O}_{3}$ engineering ceramics, J. Manuf. Process. 15 (2013) 374-388

93. P.B. Patole, V.V. Kulkarni, Experimental investigation and optimization of cutting parameters with multi response characteristics in MQL turning of AISI 4340 using nano fluid, J. Cogent Eng. 4 (2017) 1-14

94. P.B. Patole, V.V. Kulkarni, Optimization of process parameters based on surface roughness and cutting force in MQL turning of AISI 4340 using nano fluid - PMME 2016, J. Mater. Today Proc. 5 (2018) 104-112

95. P.B. Patole, V.V. Kulkarni, Parametric optimization of minimum quantity lubrication in turning of AISI 4340 using nano fluids, J. Mater. Today Proc. 5 (2018) 12419-12425

96. P.B. Patole, V.V. Kulkarni, Prediction of surface roughness and cutting force under MQL turning of AISI 4340 with nano fluid by using response surface methodology, J. Manuf. Rev. 5 (2018) 5

Cite this article as: Pralhad B. Patole, Vivek V. Kulkarni, Sudhir G. Bhatwadekar, MQL Machining with nano fluid: a review, Manufacturing Rev. 8, 13 (2021) 